\title{
Spontaneous nucleation in hypoeutectic Al-Cu system by controlled diffusion solidification process
}

\author{
Abbas A. Khalaf ${ }^{1} \cdot$ Kifah J. Takrouri $^{1}$ \\ Received: 10 February 2020 / Accepted: 25 June 2020 / Published online: 6 July 2020 \\ (c) Springer Nature Switzerland AG 2020
}

\begin{abstract}
Controlled diffusion solidification (CDS) is a promising casting process. It involves the mixing of two precursor alloys that have different masses and temperatures. Small-sized globular grains appear in the microstructure formed in the process, where a grain refiner does not need to be added. Heterogeneous nucleation and spontaneous nucleation occur during the mixing step. The heterogeneous nucleation occurs at the crucible wall, while the spontaneous nucleation takes place in a supersaturated solution exposed to high undercooling and high cooling rates established during the mixing step. A one-dimensional model was built based on the computational fluid dynamics technique to numerically predict the redistribution of the temperature and solute in the model. The two-step nucleation theory was employed to theoretically provide a better understanding of the probability of copious spontaneous nucleation taking place in the supersaturated solution. The results indicate that the spontaneous nucleation strongly depends on the concentration of the alloys, thermal gradient between the two precursor alloys, the undercooling forming during the mixing, and the supersaturation parameter for the supersaturated solution. The microstructure of the CDS process was compared with that for the conventional casting process; the results show that the small size and non-dendritic microstructure formed with a low superheat for mixed alloys happens from copious nucleation taking place during the mixing step in the CDS process. The numerical results were validated with experimental observations and scanning electron microscopy.
\end{abstract}

Keywords Controlled diffusion solidification $\cdot$ Nucleation $\cdot$ Modeling $\cdot$ SEM $\cdot$ Al alloys

\begin{tabular}{|c|c|c|}
\hline & $C_{\mathrm{PLCu}}$ \\
\hline \multicolumn{2}{|c|}{ Alloy 1 , Alloy 2 Precursor alloys } & $D$ \\
\hline Alloy 3 & Resultant desired alloy & $D_{\mathrm{o}}$ \\
\hline Atw & Solution atomic weight $\left(\mathrm{g} \mathrm{atom}^{-1}\right.$ ) & $f_{s}$ \\
\hline $\mathrm{At}_{\mathrm{Al}}$ & Pure $\mathrm{Al}$ atomic weight $\left(\mathrm{g}\right.$ atom $\left.^{-1}\right)$ & $\overrightarrow{f_{\mathrm{L}}}$ \\
\hline $\mathrm{At}_{\mathrm{Cu}}$ & Pure $\mathrm{Cu}$ atomic weight $\left(\mathrm{g}\right.$ atom $\left.^{-1}\right)$ & $\Delta G_{V}$ \\
\hline$C_{\mathrm{Cu}}$ & Copper concentration wt\% & $\Delta G^{*}$ \\
\hline$C_{0}$ & Alloy 3 concentration & Is \\
\hline$C_{1}$ & Alloy 1 concentration (wt\%) & $K_{\mathrm{L}}$ \\
\hline$C_{2}$ & Alloy 2 concentration (wt\%) & \\
\hline$C_{1}(S)$ & Prefactor & $K_{\mathrm{o}}$ \\
\hline$C_{\mathrm{PL}}$ & Specific heat of liquid $\left(\mathrm{J} \mathrm{kg}^{-1} \mathrm{~K}^{-1}\right)$ & $K_{\mathrm{b}}$ \\
\hline$C_{\mathrm{PS}}$ & Specific heat of solid $\left(\mathrm{J} \mathrm{kg}^{-1} \mathrm{~K}^{-1}\right)$ & $L$ \\
\hline$C_{\text {PLAL }}$ & Specific heat of pure $\mathrm{Al}\left(\mathrm{J} \mathrm{kg}^{-1} \mathrm{~K}^{-1}\right)$ & \\
\hline
\end{tabular}

Specific heat of pure $\mathrm{Cu}\left(\mathrm{J} \mathrm{kg}^{-1} \mathrm{~K}^{-1}\right)$
Diffusion coefficient $\left(\mathrm{m}^{2} \mathrm{~s}^{-1}\right)$
Pre-exponential factor $\left(\mathrm{m}^{2} \mathrm{~s}^{-1}\right)$
Solid fraction
Liquid fraction
Change in Gibbs free energy for volume
Change in Gibbs free energy
Nucleation rate
Liquid thermal conductivity $\left(\mathrm{W} \mathrm{m}^{-1}\right.$
$\left.\mathrm{C}^{-1}\right)$
Partition ratio
Boltzmann constant
Latent heat of fusion $\left(\mathrm{J} \mathrm{kg}^{-1}\right)$

Abbas A. Khalaf, abbasklf6@yahoo.com; abbasklf6@gmail.com | 'Department of Mechanical Engineering, McMaster University, 1280 Main Street W, Hamilton, ON L8S 4L7, Canada. 


\begin{tabular}{|c|c|}
\hline$L_{\mathrm{v}}$ & $\begin{array}{l}\text { Latent heat of fusion per unit volume } \\
\left(\mathrm{J} \mathrm{m}^{-3}\right)\end{array}$ \\
\hline$n^{\mathrm{Cr}}$ & Number of $r^{*}$ \\
\hline $\mathrm{mr}$ & $\begin{array}{l}\text { Mass ratio }\left(\mathrm{m}_{1} / \mathrm{m}_{2}\right) \text { of the two precursor } \\
\text { alloys }\end{array}$ \\
\hline$N_{\mathrm{av}}$ & Avogadro number $\left(\right.$ atom $\left.^{-1}\right)$ \\
\hline$N_{\mathrm{L}}^{\mathrm{d}}$ & Number of solute atoms \\
\hline$Q$ & Activation energy $\left(\mathrm{J} \mathrm{mole}^{-1}\right)$ \\
\hline$q$ & Heat source $\left(\mathrm{W} \mathrm{m}^{-3}\right)$ \\
\hline$R_{\mathrm{g}}$ & Gas constant $\left(\mathrm{J}\right.$ mole $\left.{ }^{-1} \mathrm{~K}^{-1}\right)$ \\
\hline$r^{*}$ & Nucleus critical radius (m) \\
\hline$T$ & Actual temperature $(\mathrm{K})$ \\
\hline$T_{1}$ & Alloy 1 temperature $(\mathrm{K})$ \\
\hline$T_{2}$ & Alloy 2 temperature $(\mathrm{K})$ \\
\hline$T_{\mathrm{C}}$ & Minimum temperature $(\mathrm{K})$ \\
\hline$T_{\mathrm{m}}$ & Melting temperature of pure solvent (K) \\
\hline$T_{\text {Liq }}$ & Liquidus temperature $(\mathrm{K})$ \\
\hline$T_{\mathrm{S}}$ & Solidus temperature $(\mathrm{K})$ \\
\hline$\Delta T$ & $\begin{array}{l}\text { Undercooling below liquidus tempera- } \\
\text { tures }(\mathrm{K})\end{array}$ \\
\hline$t$ & Time (s) \\
\hline$t_{\mathrm{n}}$ & Inoculation time (s) \\
\hline$t_{c}$ & Time at minimum temperature (s) \\
\hline$s$ & Supersaturation factor \\
\hline V & Volume \\
\hline$V_{\mathrm{m}}$ & Atomic volume $\left(\mathrm{m}^{3}\right)$ \\
\hline$x_{1}, x_{2}$ & Model dimensions (m) \\
\hline$X_{\text {Th }}$ & Thermal diffusion length (m) \\
\hline$X_{\mathrm{Cu}}$ & Solute diffusion length $(\mathrm{m})$ \\
\hline$\rho_{\mathrm{L}}$ & Liquid density $\left(\mathrm{kg} \mathrm{m}^{-3}\right)$ \\
\hline$\rho_{\mathrm{S}}$ & Solid density $\left(\mathrm{kg} \mathrm{m}^{-3}\right)$ \\
\hline$\beta_{\mathrm{T}}$ & Coefficient of thermal expansion \\
\hline$\beta_{C}$ & Coefficient of solute expansion \\
\hline$a$ & Thermal diffusivity $\left(\mathrm{m}^{2} \mathrm{~s}^{-1}\right)$ \\
\hline$\Gamma$ & Gibbs-Thomson coefficient $\left(\mathrm{m}^{\circ} \mathrm{C}\right)$ \\
\hline$\Delta \mu$ & Change in chemical potential $(\mathrm{J} / \mathrm{kg})$ \\
\hline
\end{tabular}

\section{Introduction}

Controlled diffusion solidification (CDS) is a new casting process depending on mixing of two precursor alloys that have different thermal masses to make a desirable alloy. The microstructure was non-dendritic having small size grains forming at a different cast and wrought aluminum alloys. The small size grains form from copious nucleation occurring during the steps of a successful CDS process without needing to add a grains refiner [1-5]. Accordingly, the CDS process circumferences the complex dendritic microstructure problems like the hot tearing tendencies associated with the conventional casting $[6,7]$.

Apelian et al. [8] predicted the first observation for the CDS process mechanism. They found that the nucleation would occur from undercooled liquid distributed in the resultant mixture of $\mathrm{Al}-4.5 \mathrm{wt} \% \mathrm{Cu}$ formed from mixing of pure Al with $\mathrm{Al}-33 \mathrm{wt} \% \mathrm{Cu}$. Apelian also found that the stable growth strongly depends on the difference between the Gibbs free energy for pure aluminum and the resultant alloy. After that, Symeonidis [9] studied the mechanism of the CDS process by using the same procedure used by Apelian. Symeonidis found that the mechanism depends on three steps, mixing, nucleation, and growth; and the nucleation occurs in the striations formed from undercooled pure aluminum established during the mixing step.

Recently, Khalaf [5] investigated the mechanism of the CDS process. The mechanism can be explained in three stages: mixing, nucleation, and growth. Khalaf presented a model built based on CFD technique to predict the redistribution of the temperature and the solute in the model; the results indicated that the probability of the nucleation can occur in an undercooled area existing at the boundary between the precursor alloys that blend during the mixing step.

Until now, the nucleation in the CDS process has been presented as an event occurring in an undercooled area, without applying any of the nucleation theories such as classical nucleation theory (CNT). The CNT states that the homogenous nucleation needs a high undercooling to form from pure metals [10]. However, the CDS process offers less undercooling [3], and thus, it would be difficult to produce homogeneous nucleation from pure metals. Meanwhile, heterogeneous nucleation needs a catalyst [11], which is either available at the mold wall or conventionally added as a grain refiner [12]. Therefore, during the $\mathrm{CDS}$, heterogeneous nucleation can occur only at the crucible surface from the undercooled precursor alloy. However, this is not the case to form copious nuclei growing in stable condition that was proved for the CDS process $[1,5,13,14]$.

The two-step nucleation theory generalizes from the classical nucleation theory to present the nucleation from undercooled supersaturation solution precisely [15]. The theory was proved after many experiments and simulations carried out on different systems such as water vapor [16], protein formation [17], solid-solid transition in metals and alloys [18], and p-aminobenzoic acid [19]. It was built based on the fact that the nucleation can occur by creating fluctuations in the density within the system, starting at the higher density locations. The theory suggests that the nucleation can be optimized by shifting the phase region of the liquid with a higher density, or by enabling the fluctuations within the liquid.

In this study, the probability of occurring spontaneous nucleation in the CDS process was studied in detail. The two-step nucleation theory was successfully applied to solve and prove the probability of copious nucleation 
Table 1 Experimental designations with independent parameters and constants for the laboratory CDS experiments

\begin{tabular}{|c|c|c|c|c|c|c|c|c|}
\hline \multirow[t]{2}{*}{ Designation } & \multicolumn{3}{|l|}{ Alloy 1} & \multicolumn{3}{|l|}{ Alloy 2} & \multirow[t]{2}{*}{$\mathrm{mr}$} & \multirow{2}{*}{$\begin{array}{l}\text { Alloy } \\
3 \text { Co } \\
\text { (wt } \%)\end{array}$} \\
\hline & Mass (g) & $T_{1}\left({ }^{\circ} \mathrm{C}\right)$ & $T_{\text {Liq }}\left({ }^{\circ} \mathrm{C}\right)$ & Mass (g) & $T_{2}\left({ }^{\circ} \mathrm{C}\right)$ & $T_{\text {Liq }}\left({ }^{\circ} \mathrm{C}\right)$ & & \\
\hline $\begin{array}{l}\text { Ex1 } \\
\text { (CDS and quenching) }\end{array}$ & 63 & 665 & 660 & 10.5 & 560 & 549 & 6 & 4.7 \\
\hline $\begin{array}{l}\text { Ex2 } \\
\text { (CDS and quenching) }\end{array}$ & 54 & 670 & 660 & 17.5 & 560 & 549 & 3 & 7.7 \\
\hline $\begin{array}{l}\text { Ex3 } \\
\text { (CDS and M. quenching) }\end{array}$ & \multicolumn{8}{|c|}{$\mathrm{CDS}$ (Ex6 parameters, $T_{1}$ at $665^{\circ} \mathrm{C}$ ) poured into cold quenchant at $-18^{\circ} \mathrm{C}$} \\
\hline $\begin{array}{l}\text { Ex4 } \\
\text { (M. quenching) }\end{array}$ & \multicolumn{8}{|c|}{$350 \mathrm{~g}$ of $\mathrm{Al}-4.7 \mathrm{wt} \% \mathrm{Cu}$ poured into cold quenchant at $-18^{\circ} \mathrm{C}$} \\
\hline $\begin{array}{l}\text { Ex5 } \\
\text { (M. quenching) }\end{array}$ & \multicolumn{8}{|c|}{$350 \mathrm{~g}$ of $\mathrm{Al}-7.7 \mathrm{wt} \% \mathrm{Cu}$ poured into cold quenchant at $-18^{\circ} \mathrm{C}$} \\
\hline $\begin{array}{l}\text { Ex6 } \\
(\mathrm{CDS})\end{array}$ & 290 & 667 & 660 & 47 & 555 & 549 & 6 & 4.7 \\
\hline $\begin{array}{l}\text { Ex7 } \\
(C D S)\end{array}$ & 290 & 675 & 660 & 47 & 555 & 549 & 6 & 4.7 \\
\hline $\begin{array}{l}\text { Ex8 } \\
(C D S)\end{array}$ & 290 & 688 & 660 & 47 & 555 & 549 & 6 & 4.7 \\
\hline $\begin{array}{l}\text { Ex9 } \\
\text { (Conv.) }\end{array}$ & \multicolumn{8}{|c|}{$\begin{array}{l}350 \mathrm{~g} \text { from } \mathrm{Al}-4.7 \mathrm{wt} \% \mathrm{Cu} \text { poured at } 670^{\circ} \mathrm{C} \text { into hot crucible preheated to } \\
560^{\circ} \mathrm{C}\end{array}$} \\
\hline $\begin{array}{l}\text { Ex10 } \\
\text { (Conv.) }\end{array}$ & \multicolumn{8}{|c|}{$\begin{array}{l}\text { Conventional casting for } \mathrm{Al}-4.7 \mathrm{wt} \% \mathrm{Cu} \text { remelted at } 655^{\circ} \mathrm{C} \text { and solidified } \\
\text { in the same crucible }\end{array}$} \\
\hline
\end{tabular}

taking place in an Al-Cu metal system cast via the CDS process. The experimental evidence coupled with a numerical model supported the discussion in this work.

\section{Experiments}

Table 1 shows the designation of the experiments along with the independent parameters and the constants for all the experiments carried out in the present study. Alloy 1, Alloy 2, and Alloy 3 with $\mathrm{mr} 6$ and 3 demonstrated in Table 1 were placed in the $\mathrm{Al}-\mathrm{Cu}$ phase diagram shown in Fig. 1 a.

Two CDS experiments, named Ex1 and Ex2, were carried out by direct mixing of Alloy 1 (pure Al) into Alloy 2 (Al-33 wt $\% \mathrm{Cu}$ ) shown in Fig. 1b, with mass ratio $(\mathrm{mr})$ of 6 and 3 to make the resultant alloy (Alloy 3 ) with concentrations of $\mathrm{Al}-4.7$ and $\mathrm{Al}-7.7 \mathrm{wt} \% \mathrm{Cu}$, respectively. Then, the mixture was directly quenched by the vacuum ribbon caster widely discussed by Khalaf and Shankar [20] to prepare ribbons for the CDS process. The cooling rate employed by the ribbon caster was reported to range from $10^{4} \mathrm{~K} / \mathrm{s}$ [21] to more than $10^{6}{ }^{\circ} \mathrm{C} / \mathrm{s}$ [22]. The solidified samples in the form of small broken ribbons were collected and prepared to make samples for scanning electron microscopy
(SEM) examination. The SEM analysis was carried out on the mounted samples with a JEOL JSM-7000F. ${ }^{1}$

CDS experiment named Ex3 was carried out by mixing Alloy 1 into Alloy 2 through a 9-mm-diameter funnel with $\mathrm{mr} 6$ and Alloy 1 temperature being $665^{\circ} \mathrm{C}$ to make the resultant alloy with a concentration of $\mathrm{Al}-4.7 \mathrm{wt} \% \mathrm{Cu}$; the mixture was quenched directly into moderate quenchant at $-18^{\circ} \mathrm{C}$. Figure $1 \mathrm{C}$ shows a schematic diagram demonstrating the mixing step through the funnel. The smallest thickness area, between $500 \mu \mathrm{m}$ to $1 \mathrm{~mm}$, was chosen to make samples for the SEM examination. The quenchant was made from a mixture of commercial antifreeze solution and dry ice [1]. Two conventional casting experiments for Al-4.7 wt\% Cu and Al-7.7 wt\% Cu alloys named Ex4 and Ex5, respectively, were quenched directly at $5{ }^{\circ} \mathrm{C}$ superheat into the moderate quenchant as in Ex3.

Three CDS experiments, Ex6, Ex7, and Ex8, were carried out by mixing Alloy 1 into Alloy 2 through a $6-\mathrm{mm}$ diameter funnel with $\mathrm{mr} 6$ and Alloy 1 temperature being 667,675 , and $688^{\circ} \mathrm{C}$, respectively; the mixture solidified in the same crucible as that of Alloy 2. The conventional process experiment named Ex 9 was carried out by pouring $350 \mathrm{~g}$ of $\mathrm{Al}-4.7 \mathrm{wt} \%$ at $670^{\circ} \mathrm{C}$ into a hot empty crucible preheated to $560^{\circ} \mathrm{C}$ through a 6-mm-diameter funnel as shown in Fig. $1 \mathrm{~d}$. The temperature was measured by a thermocouple inserted into the empty crucible. Samples

1 JEOL is a trademark of Japan Electron Optics Ltd., Tokyo. 
Fig. 1 a Al-Cu phase diagram showing the location of Alloy 1 , Alloy 2, and Alloy 3, b schematic diagram for CDS process showing direct mixing step, c schematic diagram for CDS process showing mixing through a funnel, $\mathbf{d}$ schematic diagram for conventional casting poured into an empty hot crucible, and e half of solidified samples for Ex6 to Ex10 experiments showing the location pointed by square for the optical microstructure images specimen

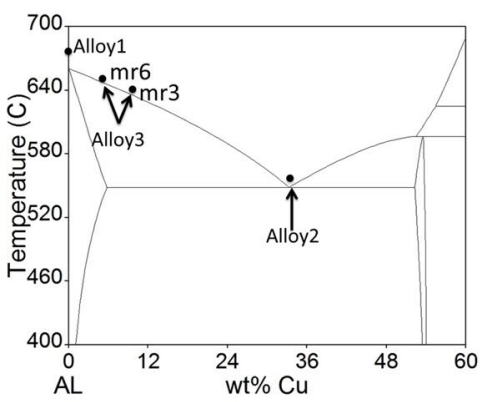

(a)

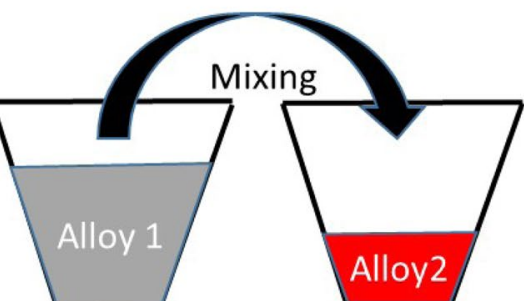

(b)

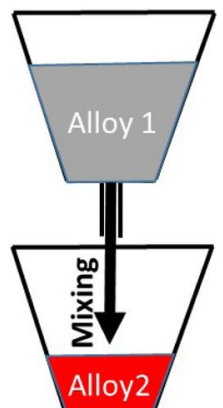

(c)

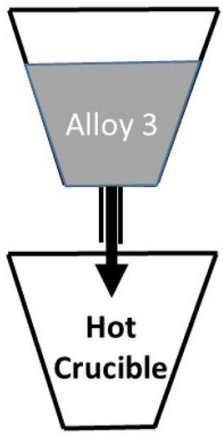

(d)

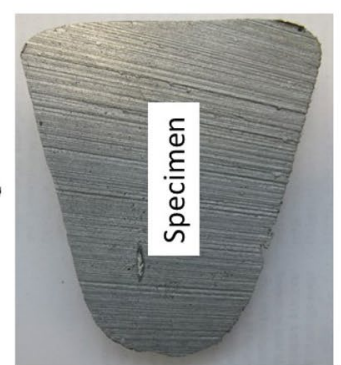

(e) from Ex6 and Ex7 were remelted and solidified into the same crucible to represent the conventional casting process experiment named Ex10. The solidified samples from Ex1 to Ex10 were prepared for optical microscope images and scanning electron microscopy tests. A stereo microscope type NIKON ${ }^{2}$ AZ 100 MI was used. Figure 1e shows half of the solidified samples for the experiments Ex6 to Ex10 showing the location of the optical microstructure images specimen pointed by square. Samples from Ex 1 to Ex10 were remelted to quantify the liquidus temperature for the resultant alloy, Alloy 3, from the transient thermal data taken from the thermocouple inserted in Alloy 3 and obtained during the cooling and solidification process. The results showed that the nucleation occurred at 649 and $640^{\circ} \mathrm{C}$, which confirmed that the compositions for Alloy 3 were $\mathrm{Al}-4.7 \mathrm{wt} \% \mathrm{Cu}$ and $\mathrm{Al}-7.7 \mathrm{wt} \% \mathrm{Cu}$, respectively.

\footnotetext{
$\overline{2}$ NIKON AZ $100 \mathrm{M}$ is a trademark of Eberbach Corporation, Ann Arbor, MI.
}

\section{Spontaneous nucleation in a supersaturated solution}

The generalized CNT can be applied to a supercooled liquid and supersaturated solution to form a crystal. The fluctuation in solute and density with high cooling rate can form clusters with critical size $\left(r^{*}=2 \sigma_{S L} / \Delta G_{V}\right)$, where $\Delta G_{\mathrm{V}}=L_{\mathrm{V}} \Delta T / T_{\mathrm{L}}$ and $\Delta G_{\mathrm{V}}=-\Delta \mu / V_{\mathrm{m}}$ for pure aluminum and $\mathrm{Al}-\mathrm{Cu}$ supersaturated solution, respectively, and $V_{\mathrm{m}}=\mathrm{Atw} / \rho_{\mathrm{s}}$ [23], Atw $=\mathrm{Ccu}(\mathrm{at} \%) \mathrm{At}_{\mathrm{Cu}}+\mathrm{C}_{\mathrm{Al}}(\mathrm{at} \%)$ $\mathrm{At}_{\mathrm{Al}}, \mathrm{At}_{\mathrm{Cu}}=63.546 \mathrm{~g} /$ atom, $\mathrm{At}_{\mathrm{Al}}=26.981 \mathrm{~g} / \mathrm{atom}$, and $\rho_{\mathrm{s}}=2535.65+26.215 \mathrm{Cu}$ extrapolated from experimental data [24]. The chemical potential is $\Delta \mu=R_{\mathrm{o}} T S$, where $S$ is the supersaturation ratio equal to zero at liquidus line, and $S=\operatorname{Ln}\left(C / C_{\text {sat }}\right)$ is a positive fraction at less than the liquidus temperature, where $C$ and $C_{\text {sat }}$ are the concentration and the concentration at saturated state, respectively [25]. $S=\operatorname{Ln}\left(C / C_{\text {sat }}\right)$ can be applied for hypereutectic alloys such as the $\mathrm{Al}-\mathrm{Si}$ system, where $\left(C / C_{\text {sat }}\right)>1$. Further, the value of $S=\operatorname{Ln}\left(C / C_{\text {sat }}\right) \approx\left(C-C_{\text {sat }}\right) /\left(100-C_{\text {sat }}\right)$ was reported to be an acceptable approximation for the chemical potential $\Delta \mu$ [19]. $S=\left(C_{\mathrm{L}}-C_{\mathrm{Cu}}\right) /\left(C_{\mathrm{L}}-C_{\mathrm{S}}\right)$ was used for Al-Cu hypoeutectic [26], for Ccu of less than the maximum solubility (5.7 wt\%), where $S=0$, positive fraction, and 1 at the liquidus line, between the liquidus and solidus lines, and at the solidus line, respectively. The concentrations in the $S$ 
Fig. 2 a Comparison between critical free energy for aluminum as a solvent and for undercooled supersaturated liquid for $\mathrm{Al}-1$ wt $\%$ Cu, b effect of the undercooling on the supersaturation factor at different copper concentrations, c schematic diagram showing the transient distribution of Alloy 1 and Alloy 2 during the mixing, $\mathbf{d}$ schematic diagram showing the location of the CDS model taken between Alloy 1 and Alloy 2, and $\mathbf{e}$ schematic diagram of the one-dimensional CDS model showing the boundary conditions and the direction of the heat and solute transfer

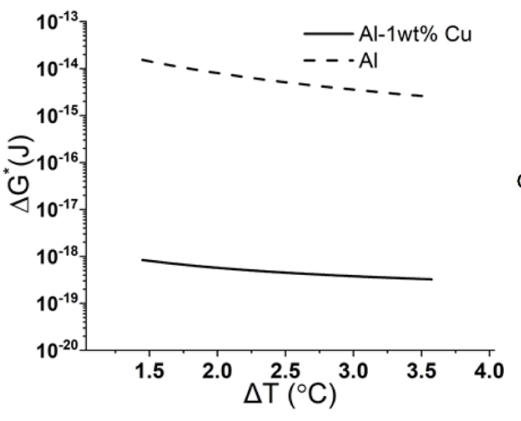

(a)

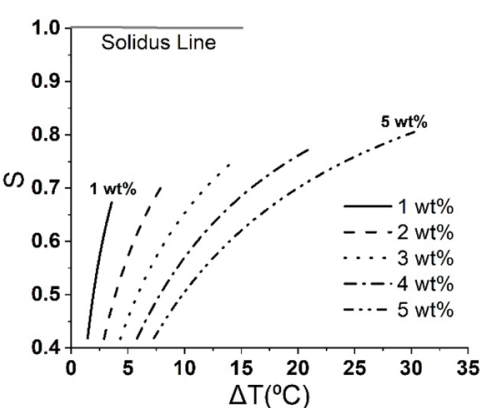

(b)

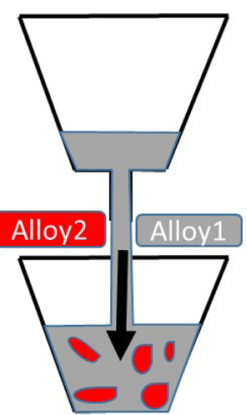

(c)

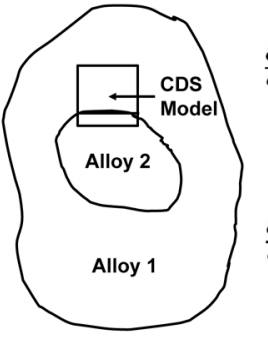

(d)

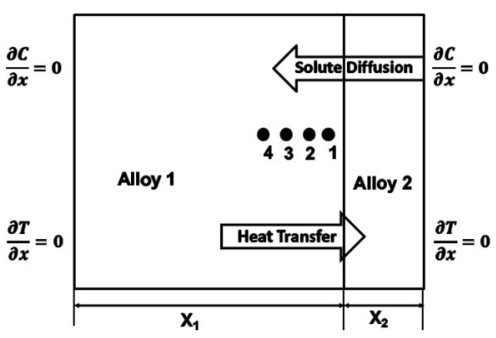

(e) equation were extrapolated from the $\mathrm{Al}-\mathrm{Cu}$ phase diagram in atom\%.

Equation (1) can be used to predict the nucleation rate $\mathrm{Is}(S)\left(\mathrm{s}^{-1} \mathrm{~V}^{-1}\right)$ as a function of $(S)$. The Is $(S)$ is defined as the probability to make critical nuclei during the cooling of an alloy. In Eq. (1), $k_{\mathrm{b}}=1.3806 \times 10^{-23}, C_{1}(\mathrm{~S})=\left[8 \pi D_{\mathrm{L}}\left(\sigma_{\mathrm{SL}}\right)^{2}\right.$ $\left.N_{\mathrm{L}}\right] /\left(a^{4} \Delta G_{\mathrm{V}}^{2}\right), a=361.49 \times 10^{-12} \mathrm{~m}$ and $404.9 \times 10^{-12} \mathrm{~m}$ for copper and aluminum, respectively, $N_{\mathrm{L}}=\left[\left(\mathrm{C}_{\mathrm{cu}}\right) \rho_{\mathrm{S}} N_{\mathrm{av}}\right] / \mathrm{Atw}$ represents the number of copper atoms in the molten alloy, and $N_{\mathrm{av}}=6.22 \times 10^{23}$ atoms $^{-1}$. Further, in Eq. (1), the free energy $\left(\Delta G^{*}(S)=16 \pi \sigma_{\mathrm{SL}}^{3} / 3 \Delta G_{\mathrm{V}}\right)$ represents the energy barrier to the nucleation as a function of $(S)$, where $\sigma_{\mathrm{SL}}$ is $0.116 \mathrm{~J} / \mathrm{m}^{2}$ [27] and $\sigma_{\mathrm{SL}}=\Gamma L_{v} / T_{\text {Liq }}$ [28] for pure aluminum and $\mathrm{Al}-\mathrm{Cu}$ solution, respectively, and $\Gamma=1.595 \times 10^{-7}-\left(1.595 \times 10^{-9}\right) \mathrm{Ccu}, L_{v}=L \rho_{S}$, and $L=385000-717 \mathrm{Cu}$ were extrapolated from experimental data [24]. The spontaneous nucleation occurs at very short time in the liquid solution when $\Delta G^{*}(S)$ approaches zero [29], and the calculations for $\Delta G^{*}(S)$ and Is $(S)$ strongly depend on the value of $\sigma_{\mathrm{SL}}$, which is in a range from 30 to $250 \mathrm{mJm}^{-2}$ for liquid metals and alloys [18].

Equation (2) can be used to predict the number of nuclei forming to have a critical size [10]. $\Delta G^{*}(S)=T k_{\mathrm{b}} \operatorname{Ln}\left(N_{\mathrm{L}}\right)$ is the free energy at $n^{\mathrm{cr}}=1$; Eq. (3) is found by mathematical manipulation to predict the supersaturation ratio $\left(S_{1}\right)$ as a function of $(T)$ and $C_{\mathrm{cu}}$ at the beginning of the nucleation events. Further, $S_{1}=\left(C_{\mathrm{cu}}(\mathrm{at} \%) / C_{\mathrm{L}}\left(k_{\mathrm{o}}-1\right)\right)-\left(1 /\left(k_{\mathrm{o}}-1\right)\right)$ can be predicted as a function of $C_{\mathrm{cu}}$, where $k_{\mathrm{o}}=0.1277$ is the partition ratio extrapolated from the $\mathrm{Al}-\mathrm{Cu}$ phase diagram on at $\%$. $S_{1}$ was calculated by the iteration technique, which starts by changing $C_{\mathrm{cu}}$ (at $\left.\%\right)$ to calculate $T_{\mathrm{Liq}}=660.45-5.90175 C_{\mathrm{cu}}+$ $0.03406\left(C_{\mathrm{cu}}\right)^{2}-0.00355\left(C_{\mathrm{cu}}\right)^{3}-5.62833 \times 10^{-6}\left(C_{\mathrm{cu}}\right)^{-4}, T_{\mathrm{s}}=66$ $0.45-45.77569 C_{\mathrm{cu}}-2.1527\left(C_{\mathrm{cu}}\right)^{2}+1.04077\left(C_{\mathrm{cu}}\right)^{3}+0.01019$ ( $\left.C_{\mathrm{cu}}\right)^{4}$, and the two equations for $S_{1}$. Hence, the iteration ends when the values of $S_{1}$ are equal. $T, C_{\mathrm{Cu}^{\prime}}$ and $S_{1}$ were found at the beginning of the nucleation events. Another iteration was used to calculate Is(S), $T$, and all the other parameters starting from $S_{1}$ and increasing by a certain amount until reaching the final $T$. The $T_{\mathrm{Liq}}$ and $T_{\mathrm{S}}$ are empirical equations obtained from a regression fit of simulation data for the equilibrium binary Al-Cu phase. Further, $T_{\mathrm{S}}=549.9^{\circ} \mathrm{C}$ is for copper more than 5.7 at\%.

The time $t_{\mathrm{n}}=1 /\{\mid \mathrm{s}(S) V\}$ represents inoculation time required to form an embryo with a critical radius $\left(r^{*}\right)$ in homogenous nucleation [30]. $V$ represents the volume of the thermal boundary layer that forms the undercooled region in Alloy 1 with a depth of $\left(X_{\mathrm{Th}}\right)^{2}=4 a t$ where $a=k_{\mathrm{L}} /$ $\left(\rho_{\mathrm{L}} C_{\mathrm{PL}}\right)$ are calculated as a function of temperature and $t=2 \times 10^{-8} \mathrm{~s}$ is arbitrarily chosen within the range of nucleation of the primary Al system [31].

$I_{S}(S)=C_{1}(S) \exp \left(-\Delta G^{*}(S) / k_{\mathrm{b}} T\right)$

$n^{\mathrm{cr}}=N_{\mathrm{L}} \exp \left(-\Delta G^{*}(S) / k_{\mathrm{b}} T\right)$

$S_{1}=\left(\sqrt{16 \pi\left(V_{\mathrm{m}}^{2}\right) \sigma_{\mathrm{SL}}^{3} / 3 T k_{\mathrm{b}}\left(\operatorname{Ln}\left(N_{\mathrm{L}}\right)\right)}\right) / \mathrm{TR}_{\mathrm{o}}$. 


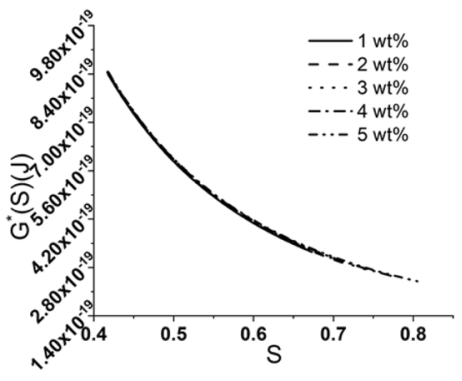

(a)

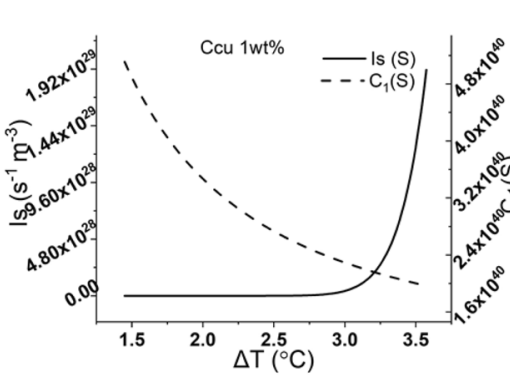

(d)

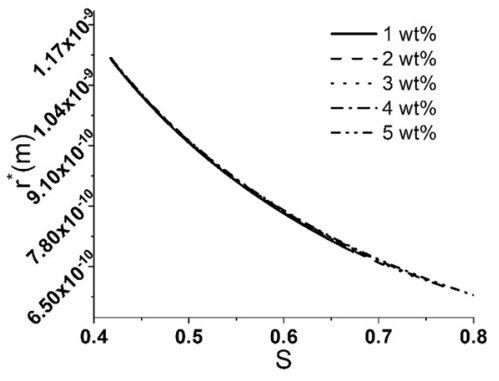

(b)

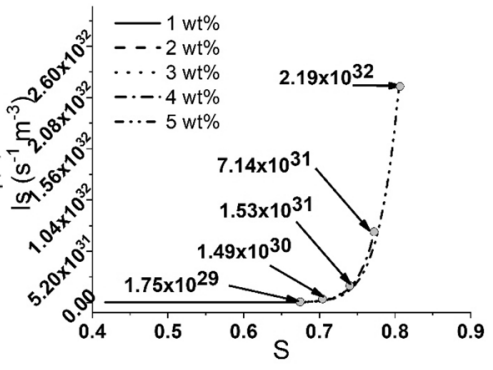

(e)

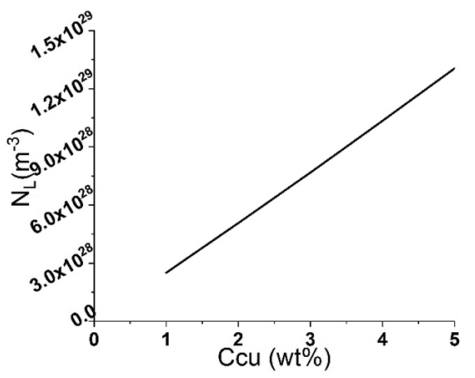

(c)

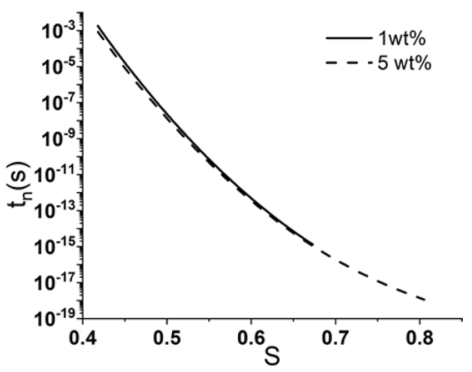

(f)
Fig. 3 a Effect of the supersaturation factor on the critical free energy at different copper concentrations, $\mathbf{b}$ effect of the supersaturation factor on the critical radius at different copper concentrations, c effect of the copper concentration on $N_{\mathrm{L}}$, d effect of the undercooling on the nucleation rate and nucleation prefactor cal- culated as a function of the supersaturation factor, e effect of the supersaturation factor on the nucleation rate at different copper concentrations, and $\mathbf{f}$ effect of the supersaturation factor on the inoculation time at different copper concentrations

process. Numerical simulations were carried out using a mathematical model to provide a better understanding of the transient thermal and solute redistribution at the end of the blending process when atomic diffusion dominated prior to the nucleation event. The model was built based on that Alloy 2 breaks down to small masses by turbulent agitation and distributes in the Alloy 1 matrix that represents the bigger mass existing in the mixture [5]. Figure $2 c$, $d$ shows a schematic diagram drawn to understand the mixing step in the CDS process. Figure $3 \mathrm{c}$ shows a schematic diagram for the mixing step, showing that the Alloy 2 breaks to small masses surrounded by Alloy 1 . This result was checked by ANSYS software. Figure $2 d$ shows a schematic diagram formulated to emulate a liquid pocket of Alloy 2 surrounded by Alloy 1. Further, Fig. $2 d$ shows the location of the one-dimensional model employed in the present study covering an area between Alloy 1 and Alloy 2. Figure 2e shows a schematic diagram for the onedimensional model having two separated domains of Alloy 1 and Alloy 2 coexisting in the liquid state in the mixture. In Fig. 2 (e), the boundary conditions appear at the outer boundary, and the heat transfers from Alloy 1 toward Alloy 2 , while the solute transports from Alloy 2 toward Alloy 1 . Further, points 1 to 4 were chosen in the Alloy 1 domain to calculate the cooling curve at different locations near 
the boundary between Alloy 1 and Alloy 2. The dimension of the model was $X_{1}+X_{2}=25 \mu \mathrm{m}$, which was chosen based on the microstructure observations from experiments already available in the literature [2], where $X_{1}$ and $\mathrm{X}_{2}$ are calculated according to the mass ratio [5]. The Peclet number was significantly less than one $(\ll 1)$ within the dimensions employed in the simulation [5], which cancels the advection effect caused by the thermal and solute gradient in the liquids, although high thermal and solute gradients exist in the Alloy 1 and Alloy 2 domains.

Equations (4) and (5) are the heat and solute diffusion equations solved numerically by the CFD technique using FORTRAN, respectively [32]. The term $q$ in Eq. (1) represents the heat generated from phase change. It was canceled in the simulation for the temperature distribution prior to the nucleation event. The parameters used in the model were as follows: $D=D_{\mathrm{o}} \exp \left[-Q / R_{\mathrm{g}} T\right]$ is the coefficient of diffusion for the liquid phase evaluated as a function of temperature, $D_{\mathrm{o}}=8.10 \times 10^{-7} \mathrm{~m}^{2} \mathrm{~s}^{-1}$ [33], $R_{\mathrm{g}}=8.31432 \mathrm{Jmole}^{-1} \mathrm{~K}^{-1}$ [33], $Q=3.89 \times 10^{4} \mathrm{Jmole}^{-1}$ [33], and $K_{\mathrm{L}}=95 \mathrm{Wm}^{-1} \mathrm{k}^{-1}$ [34]. In Eq. (4), $\rho$ was $\rho_{L}$ and $\rho_{s}=2700 \mathrm{~kg} \mathrm{~m}^{-3}$ extrapolated from Factsage ${ }^{3}$ for the liquid and solid phase, respectively; Eq. (6) can be used to evaluate $\rho_{L}$ as a function of temperature and solute concentration because there is a large difference in the temperature and the solute values between Alloy 1 and Alloy 2 at the beginning of the mixing. In Eq. (6), the parameters were $\beta_{\mathrm{T}}=-4.032+(1.654 E-2) T-(2.53 E-5) T^{2}+(1.23 E-8) T^{3}$, $\beta_{C}=22.19678+(0.1629) C+(9.0973 E-4) C^{2}+(2.004 E-5) C^{3}$ used with a temperature between 549.8 and $700{ }^{\circ} \mathrm{C}$ and $C$ from 0 to $33 \mathrm{wt} \% \mathrm{Cu}$ [5]. Further, in Eq. (4), $C_{\mathrm{P}}$ was $C_{\mathrm{PL}}$ and $C_{\mathrm{PS}}=766 \mathrm{~J} \mathrm{~kg}^{-1} \mathrm{~K}^{-1}$ [35] which were used to calculate the heat capacity of the liquid phase and solid phase, respectively; $C_{\mathrm{PL}}=C_{\mathrm{PLAl}}(\mathrm{Al} / 100)+C_{\mathrm{PLCu}}(\mathrm{Cu} / 100)$ was taken as a function of aluminum and copper concentration to achieve better accuracy in the simulation, where $C_{\text {PLAI }}=1180 \mathrm{~J} \mathrm{~kg}^{-1} \mathrm{~K}^{-1}$ and $C_{\mathrm{PLCu}}=495 \mathrm{~J} \mathrm{~kg}^{-1} \mathrm{~K}^{-1}$ [36], and $\mathrm{Al}$ and $\mathrm{Cu}$ are the aluminum and copper in wt\%, respectively. Further, in Eq. (4), $C_{\mathrm{P}}=C_{\mathrm{PS}} f_{\mathrm{s}}+C_{\mathrm{PL}}\left(1-f_{\mathrm{s}}\right)$, $\rho=\rho_{\mathrm{s}} f_{\mathrm{s}}+\rho_{\mathrm{L}}\left(1-f_{\mathrm{s}}\right), K=K_{\mathrm{s}} f_{\mathrm{s}}+K_{\mathrm{L}}\left(1-f_{\mathrm{s}}\right)$ [5], where $f_{\mathrm{s}}$ is evaluated in Eq. (7) [37] and $k_{\mathrm{o}}=0.145$ for the Al-Cu system in wt\%.

$\rho C_{\mathrm{a}} \frac{\partial T}{\partial t}=\nabla \cdot(K \nabla T)+q$

$\frac{\partial C}{\partial t}=\nabla \cdot(D \nabla C)$

\footnotetext{
${ }_{3}$ Factsage (TM) 6.1, Thermfact and GTT, Technologist-1976-2009.
}

$$
\begin{aligned}
& \rho_{\mathrm{L}}(T, C)=3150+\beta_{\mathrm{T}}(T-549.8)+\beta_{\mathrm{C}}(C-33) \\
& f_{\mathrm{s}}=1-\left(T_{\mathrm{m}}-T / T_{\mathrm{m}}-T_{\mathrm{Liq}}\right)^{1 / k_{\mathrm{o}}-1} .
\end{aligned}
$$

\section{Heterogeneous nucleation in the CDS process}

The heterogeneous nucleation occurs in the mixture at the crucible wall from the precursor alloy that has a higher liquidus temperature during the mixing step. The other precursor alloy acts as a heat sink for the first precursor alloy. The probability of copious heterogeneous nucleation increases when higher $\Delta T$ is employed between the two precursors alloys. This publication was dedicated to studying the probability of spontaneous nucleation taking place in the CDS process.

\section{Results and discussion}

Figure 3a shows $\Delta G^{*}(S)$ calculated for different $C_{\mathrm{cu}}$ starting from 1 to $5 \mathrm{wt} \% \mathrm{Cu}$. In Fig. $3 \mathrm{a}, \Delta G^{*}(S)$ was approximately within the range of $10^{-19} \mathrm{~J}$ that is required to start the spontaneous nucleation in the supersaturated solution for the Al-Cu system. The range of $\Delta G^{*}(S)$ confirms the change in free energy calculated for the protein crystal, organic, and inorganic materials nucleated from the dense liquid [38]. Figure $3 \mathrm{~b}$ shows the change in the critical radius of the copper nuclei $\left(r^{*}\right)$ with $S$ for different $C_{\mathrm{cu}}$. In Fig. 3b, the smallest $r^{*}$ forms with higher $S$ occurred at the lower $\Delta G^{*}(S)$, and $r^{*}$ would be between 0.6 and $1.2 \mathrm{~nm}$. Figure $3 c$ shows $N_{\mathrm{L}}$ as a function of $C_{\mathrm{cu}}$. In Fig. $3 c, N_{\mathrm{L}}$ proportionally increases by adding copper to the alloy. $N_{\mathrm{L}}$ was between $10^{28}$ and $10^{29} \mathrm{~m}^{-3}$ for $C_{\mathrm{cu}}$ between 1 and 5 $w t \%$, respectively, which within the range of $10^{28} \mathrm{~m}^{-3}$ is used to calculate the steady-state nucleation rate in the CNT for typical metals [10]. Figure 3d shows the change in Is $(S)$ and prefactor $\left\{C_{1}(S)\right\}$ for the undercooled liquid solution of $\mathrm{Al}-1 \mathrm{wt} \% \mathrm{Cu}$ taken as an example. In Fig. 3d, $C_{1}(S)$ continues to decrease with increasing $\Delta T$ taking the same trend in CNT [29] because $C_{1}(S)$ is a function of $1 / S^{2}$. Further, Fig. $3 d$ shows that Is $(S)$ increases at a low rate with lower $\Delta T$ and then drastically increases after $\Delta T$ of approximately $3{ }^{\circ} \mathrm{C}$. However, the nucleation rate considered from the CNT increases to reach a maximum value and then decreases because of the competition between $\Delta T$ and $T$ [29]. Figure 3e shows the change in Is $(S)$ with $C_{\mathrm{cu}}$ taken between 1 and $5 \mathrm{wt} \% \mathrm{Cu}$. In Fig. $3 \mathrm{e}$, Is(S) is significantly greater for a higher $C_{\mathrm{cu}}$ because more copper is 


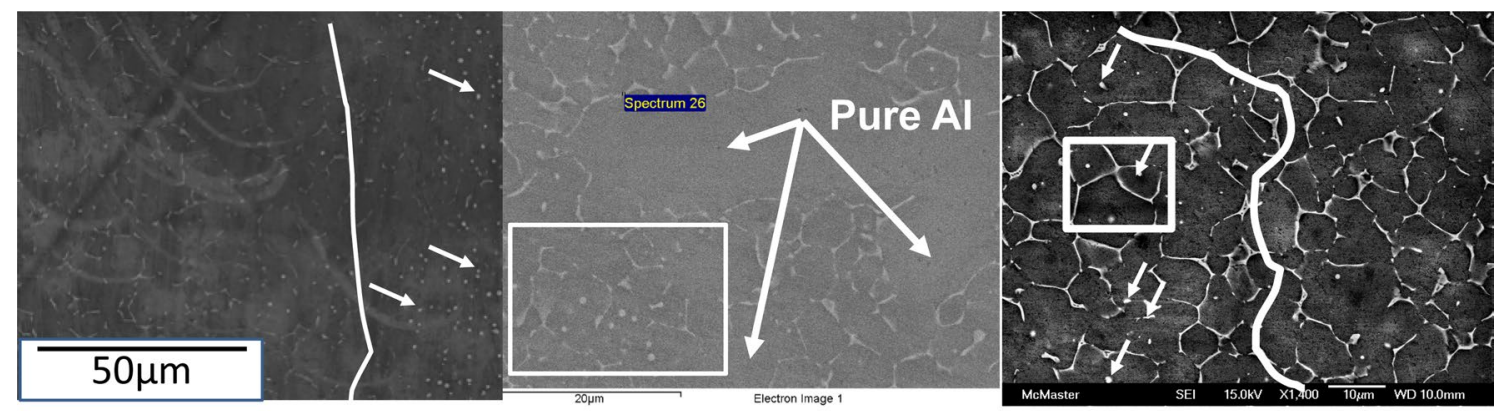

(a)

(b)

(c)

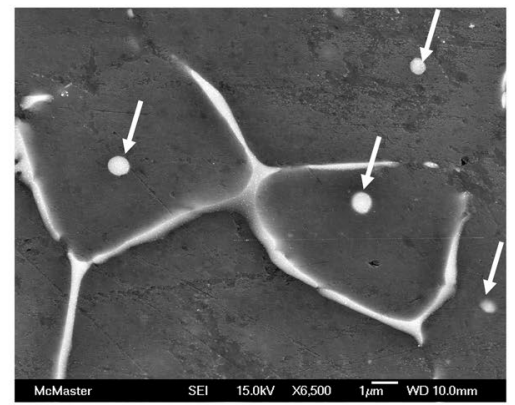

(d)

Fig. 4 a SEM microstructure image of CDS experiment Ex1 for mr 6 illustrated in Table 1, b SEM microstructure image of CDS experiment Ex2 for mr 3 illustrated in Table 1, c another SEM microstruc-

available to nucleate in the solution. The maximum values for $\mathrm{Is}(S)$ were calculated to be $1.75 \times 10^{29}, 1.49 \times 10^{30}$, $1.53 \times 10^{31}, 7.14 \times 10^{31}$, and $2.19 \times 10^{32} \mathrm{~s}^{-1} \mathrm{~m}^{-3}$ for $C_{\mathrm{cu}}$ of $1-5$ wt $\%$, which occurred at $S$ of $0.67,0.713,0.74,0.77$, and 0.8 , respectively. One can suggest that the copious spontaneous nucleation strongly depends on the undercooling and the solute concentration. Figure $3 f$ shows the effect of $C_{\mathrm{cu}}$ change on $t_{\mathrm{n}}$ calculated for $C_{\mathrm{cu}}=1$ and $5 \mathrm{wt} \%$; the $t_{\mathrm{n}}$ coordinate was drawn in logarithmic scale. In Fig. $3 f, t_{n}$ significantly decreases with increasing $(S)$, and the calculated $t_{n}$ was $10^{-3} s$ at the beginning of the nucleation $(S=0.42)$ and drastically decreases to less than $10^{-12} s$ when $S>0.6$ taken as an example. The higher $C_{\mathrm{cu}}$ would significantly decrease the $t_{n}$ to become less than $10^{-19} s$ for $S=0.8$ and $C_{\mathrm{cu}}=5 \mathrm{wt} \% \mathrm{Cu}$.

Figure $4 a-d$ shows SEM microstructure images of samples from quenched CDS experiments named Ex1 and Ex2 presented in Table 1 quenched by a copper wheel. Figure 4a shows the SEM microstructure image of a sample from the experiment named Ex1. In Fig. 4a, innumerable spherical morphologies form with gradient distribution in two areas separated by a scribble line. The morphologies pointed by arrows exist in the area having a higher number of spherical morphologies, while unregular morphologies dominate in the other area. ture image for CDS experiment Ex2, and $\mathbf{d}$ magnified SEM microstructure image for the square shown in $\mathbf{c}$

Figure $4 b, c$ shows SEM microstructure images taken from a different location for samples from the CDS experiment with $\mathrm{mr}$ of 3 named Ex2 in Table 1. In Fig. 4b, $C_{\mathrm{cu}}=0$ was quantified by an SEM point scan in different locations in the area known as pure aluminum, revealing that the time of mixing before quenching is not sufficient to diffuse the copper in the entire mixture as already reported [5]. Further, the spherical morphologies and unregular morphologies exist in the entire microstructure. The spherical morphologies increase near the pure aluminum area as shown in the area surrounded by the square. Figure $4 \mathrm{c}$ shows another area filled with different morphologies in the samples of Ex2 chosen away from the pure aluminum locations. In Fig. 4c, two areas separated by a scribble line exist in the microstructure, showing that most of the spherical morphologies pointed by arrows noticeably exist in one area and the unregular morphologies appear in the other area. Figure $4 \mathrm{~d}$ shows a magnified SEM microstructure image pointed by the square shown in Fig. 4c, revealing that the size of the spherical morphologies is clearly of less than $1 \mu \mathrm{m}$. The $\mathrm{Ccu}$ in the spherical morphologies shown in Fig. $4 a-d$ was quantified by SEM point scan, and it was found to be changed from 2 to $15 \mathrm{wt} \% \mathrm{Cu}$. The results obtained from Fig. 4a-d demonstrate that the copper 


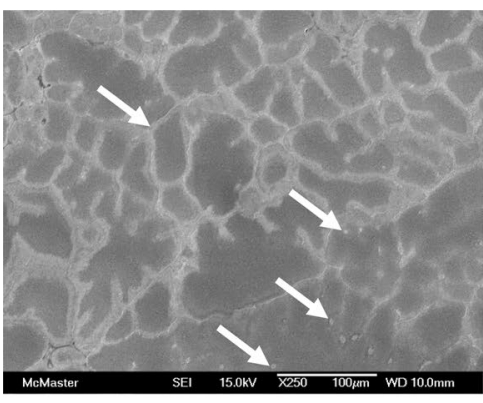

(a)

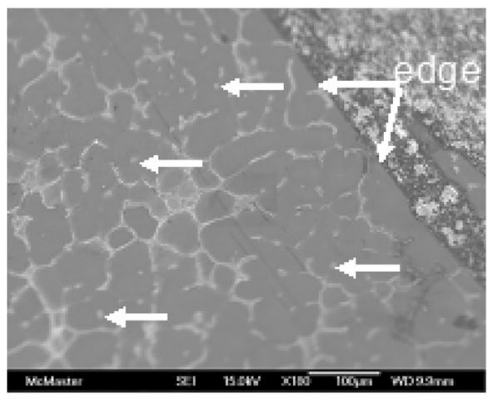

(d)

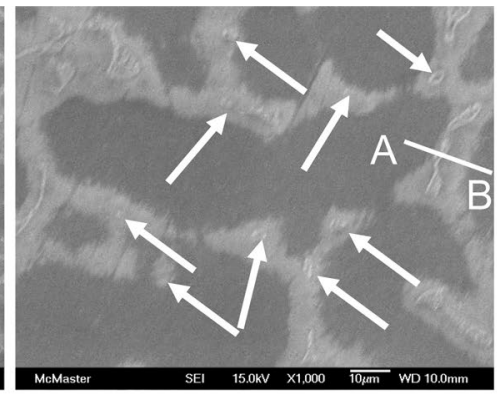

(b)

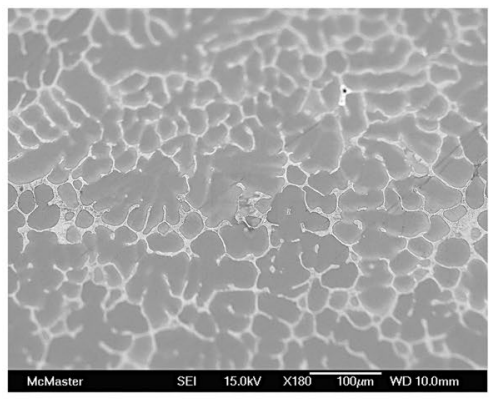

(e)

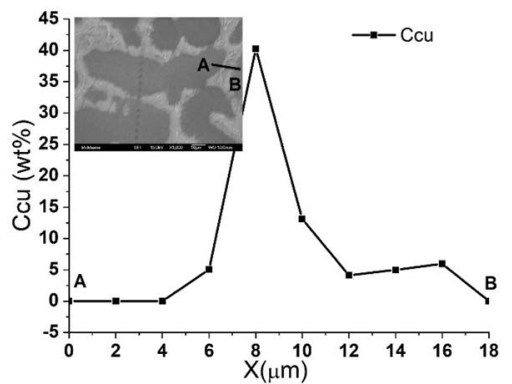

(c)

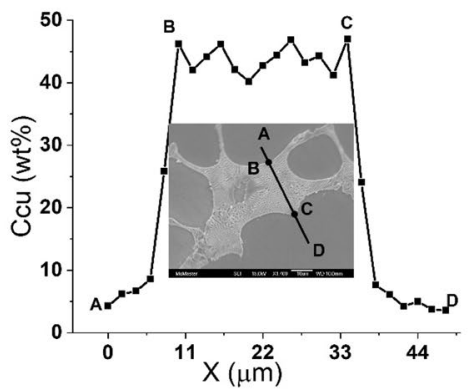

(f)
Fig. 5 a SEM microstructure image of sample for moderate quenched CDS experiment named Ex3 in Table 1, b SEM microstructure magnified image of sample for the experiment named Ex3, c SEM line scan for Ccu of sample for experiment named Ex3, d SEM microstructure image of sample for moderate quenched experiment named Ex4 in Table 1, e SEM microstructure image of sample for moderate quenched experiment named Ex5 in Table 1, and $\mathbf{f}$ SEM line scan for Ccu of sample for the experiment named Ex5 would diffuse in the mixture in a certain area of the pure aluminum, creating a gradient in the copper distribution. The probability of nucleation exists in the CDS mixture during the mixing and quenching steps; therefore, copious nucleation in a supersaturated solution takes place in the lower $C_{\mathrm{cu}}$ area exposed to a high cooling rate and certain undercooling in CDS. Then, other copious nucleation takes place in the entire mixture exposed to a high cooling rate with high undercooling during the quenching process.

Figure $5 a-f$ shows the SEM microstructure images and line scan data of samples from the experiments named Ex3, Ex4, and Ex5 exposed to a moderate quenchant. The moderate quenchant employs high undercooling and lower cooling rate compared with that for the copper wheel. Figure $5 \mathrm{a}$, b shows the SEM microstructure images for the experiments named Ex3. Figure 5a shows the copious spherical morphologies pointed by arrows distributed in the entire microstructure. Figure $5 b$ shows a magnified SEM microstructure image from another CDS sample for Ex3. In Fig. 5b, two types of morphologies, spherical shape pointed by arrows and the unregular shape, form in the microstructure. The Ccu was quantified by the SEM point scan for spherical morphologies to be between 41 and 45 wt $\% \mathrm{Cu}$.

Figure $5 c$ shows the $C_{c u}$ quantified by SEM line scan between points $A$ and $B$ crossing one of the unregular morphologies shown in Fig. $5 \mathrm{~b}$ that was overlaid in Fig. $5 \mathrm{c}$. In Fig. 5c, the Ccu changes from zero at point $A$ and $B$ to reach the maximum of $42 \mathrm{wt} \% \mathrm{Cu}$ on the unregular morphology. Figure $5 \mathrm{~d}$ shows an SEM microstructure image of a sample from conventional casting named Ex4 for Al-4.7 wt\% Cu quenched by the same moderate quenchant. In Fig. $5 d$, spherical morphologies pointed by arrows and unregular morphologies appear in the microstructure, where the spherical morphologies concentrate near the edge that is exposed to higher cooling rate and higher undercooling. The Ccu on the morphologies changes from 41 to near 50 wt\% Cu. Figure 5e shows an SEM microstructure image of a sample from conventional casting for Al-7.7 wt $\% \mathrm{Cu}$ quenched by the same quenchant. In Fig. 5e, unregular morphologies dominate in the entire microstructure, whereas the spherical morphologies would rarely form. Figure $5 f$ shows the magnified SEM microstructure images overlaid on the elemental line scan AD for Al-7.7 wt\% Cu conventional experiments named Ex5, showing that the 


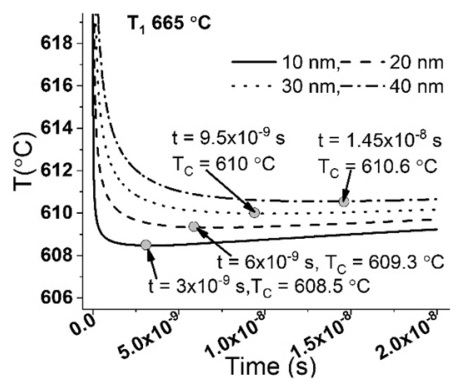

(a)

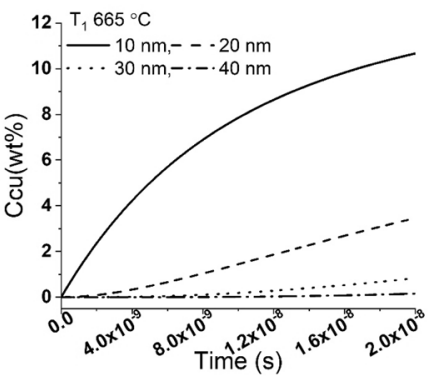

(b)

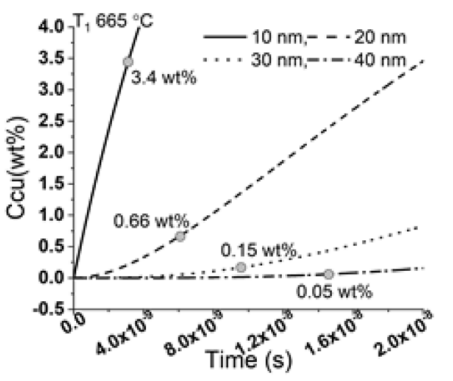

(c)

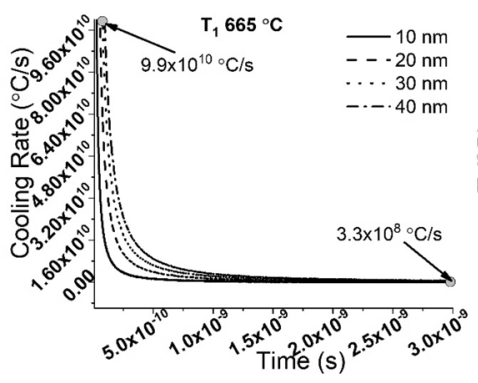

(d)

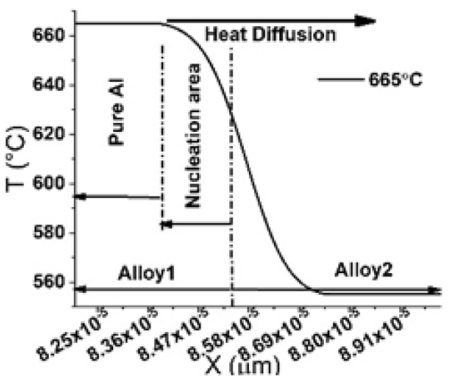

(e)

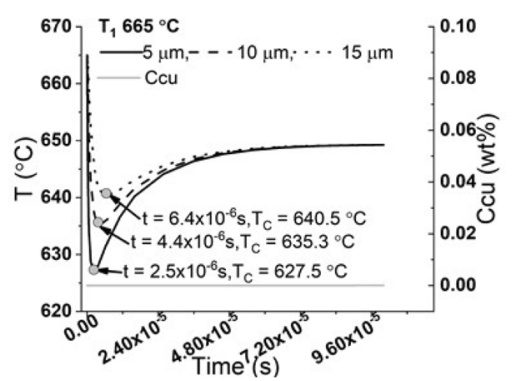

(f)
Fig. 6 a-d simulation result showing the cooling curve, copper concentration, and cooling rate for the points 1 to 4 for the experiment Ex6 in Table 1, a cooling curve, b copper concentration, c copper concentration at minimum temperature $\left(T_{\mathrm{C}}\right)$ pointed by cir-

$C_{\mathrm{cu}}$ was more than zero on the areas $A$ and $D$ and the $C_{\mathrm{cu}}$ fluctuates from 42 to around $50 \mathrm{wt} \% \mathrm{Cu}$ on the unregular morphology between points $B$ and $C$. The conclusion suggested from Fig. 5a-f is that copious spherical morphologies can form when moderate cooling rate, high undercooling, and limited $C_{\mathrm{cu}}$ employed in the supersaturated solution formed in the alloys. Further, the agitation during the mixing process is also required to enable better distribution to the nucleation in the entire mixture regardless of the size of the product. Therefore, the spherical morphologies obviously appear in the entire mixture in the CDS samples and concentrate on the edge for conventional casting for $4.7 \mathrm{wt} \% \mathrm{Cu}$. However, the spherical morphologies rarely appear in the middle of the sample of conventional casting for $C_{\mathrm{cu}}$ of 4.7 and $7.7 \mathrm{wt} \%$ Cu because of lower undercooling, lower cooling rate, and high $C_{\mathrm{cu}}$ existing in the middle of the samples.

Figure 6a-d shows the simulation results for the cooling curve, $C_{\mathrm{cu}}$ and cooling rate for points 1-4 shown in Fig. $2 \mathrm{e}$ placed in the Alloy 1 domain at 10,20,30, and $40 \mathrm{~nm}$ from the interface between Alloy 1 and Alloy 2 within the copper diffusion length $(X \mathrm{Cu})^{2}=4 D_{\mathrm{L}} t$ [39], respectively. The initial conditions $T_{1}, T_{2}, C_{1}$, and $C_{2}$ for $\mathrm{mr} 6$ were chosen for the experiment Ex6 in Table 1 to be $665^{\circ} \mathrm{C}, 555^{\circ} \mathrm{C}, 0$ wt $\%$ and $33 \mathrm{wt} \%$ for Alloy 1 and Alloy 2, respectively, to make $\mathrm{Al}-4.7 \mathrm{wt} \% \mathrm{Cu}$ as a resultant alloy (Alloy 3 ). The mesh size cle, $\mathbf{d}$ cooling rate, e temperature distribution in Alloy 1 and Alloy 2 domains covering the thermal diffusion length, and $f$ simulation results showing the cooling curve in Alloy 1 domain at $5 \mu \mathrm{m}$, $10 \mu \mathrm{m}$, and $15 \mu \mathrm{m}$

and time step were $5 \mathrm{~nm}$ and $1 \times 10^{-14} \mathrm{~s}$, respectively. Figure $6 \mathrm{a}$ shows the simulation results for the cooling curve at points $1-4$. In Fig. $6 a, T_{C}$ was $608.5,609.3,610$, and $610.9^{\circ} \mathrm{C}$ at which $d \mathrm{~T} / d \mathrm{t}=0$ leading to eliminate the nucleation after $3.5 \times 10^{-9}, 6 \times 10^{-9}, 9.5 \times 10^{-9}$, and $1.45 \times 10^{-8} \mathrm{~s}$ for points $1-4$, respectively $[11,40]$. Figure $6 \mathrm{~b}$ shows the copper concentration at points $1-4$, showing that the $C_{c u}$ builds up faster near the interface at point $1(10 \mathrm{~nm})$ and requires more time to appear at point $4(40 \mathrm{~nm})$. Figure $6 \mathrm{c}$ shows the simulation results for $C_{\mathrm{cu}}$ shown in Fig. 6b. In Fig. 6c, the $C_{\mathrm{cu}}$ pointed by circles represents the concentration at $T_{\mathrm{C}}$ shown in Fig. 6a, which reaches 3.4, 0.66, 0.15, and $0.05 \mathrm{wt} \%$ happened at the time $\left(t_{c}\right)$ of $3.5 \times 10^{-9}, 6 \times 10^{-9}$, $9.5 \times 10^{-9}$ and $1.45 \times 10^{-8} \mathrm{~s}$, respectively. The suggestion that $t_{n}$ shown in Fig. $3 \mathrm{f}$ is supposedly less than $t_{\mathrm{c}}$ to enable spontaneous nucleation occurring from a maximum number of embryos to reach the critical size in the supersaturated solution for the CDS process. Figure $6 \mathrm{~d}$ shows the cooling rate $(\Delta T / \Delta t)$ calculated at each mesh for points $1-4$. In Fig. $6 \mathrm{~d}$, the higher cooling rate would be $9.9 \times 10^{10}{ }^{\circ} \mathrm{C} / \mathrm{s}$ near the interface at the beginning of the heat diffusion; hence, the cooling rate drastically decreases to less than $3.3 \times 10^{8}{ }^{\circ} \mathrm{C} / \mathrm{s}$ after $3 \times 10^{-9} \mathrm{~s}$. This implies that $\mathrm{CDS}$ can be considered as a high cooling rate process and the $\Delta T$ employed during the CDS process depends on $T_{1}$ and $T_{2}[1$, 5]. According to the results from Fig. $6 a-d$, one can suggest 


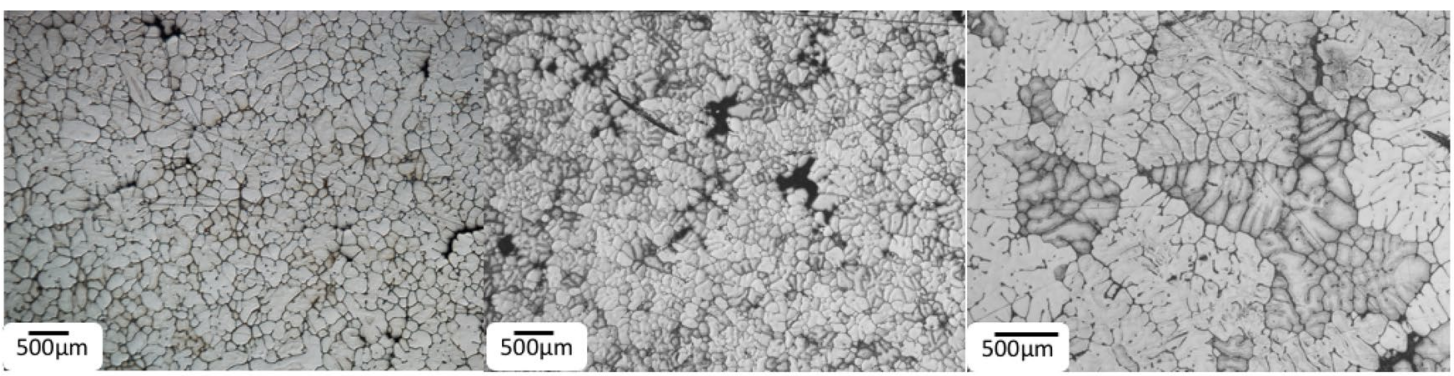

(a)

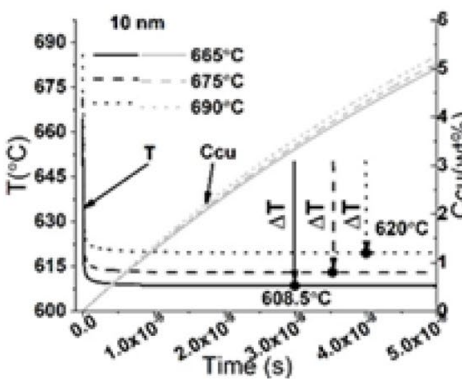

(d) (b)

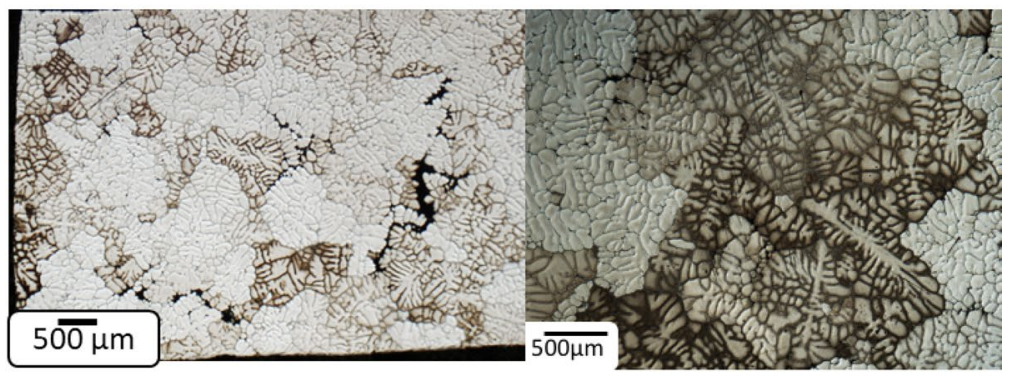

(e) (c)

(f)
Fig. $7 \mathbf{a}, \mathbf{b}$, and $\mathbf{c}$ typical light optical microstructure images for the experiments Ex6 to Ex8 listed in Table 1, a Ex6, b Ex7, c Ex8, d simulation results for cooling curve and copper concentration at point

that the copper diffuses in the Alloy 1 domain, leading to change of the pure metal to an undercooled alloy that would be exposed to a higher cooling rate with certain undercooling. This would result in a better environment for spontaneous nucleation based on the two-step nucleation theory that depends on the change in the density of the undercooled solution. Figure 6 e shows the simulation results of the temperature distribution drawn around the thermal diffusion length using the CDS model shown in Fig. 2e. In Fig. 6e, the thermal gradient between Alloy 1 and Alloy 2 would be sufficient to achieve the required $\Delta T$ shown in Fig. $2 \mathrm{~b}$ to enable spontaneous nucleation for a small $C_{\mathrm{cu}}$. The thermal and solute diffusion length always increases with the elapsed time resulting in an increase in the nucleation area. Further, the thermal gradient between Alloy 1 and Alloy 2 enhances the nucleation from Alloy 1 by enabling the heat issued during the nucleation event to transfer toward Alloy 2, contrary to the conventional casting that has only one alloy with a certain temperature [5]. Figure $6 \mathrm{f}$ shows the simulation results for the cooling curve at three points placed in the Alloy 1 domain at $5 \mu \mathrm{m}, 10 \mu \mathrm{m}$, and $15 \mu \mathrm{m}$ from the interface between Alloy 1 and Alloy 2. In Fig. 6f, the Ccu is not feasible at the points, indicating that the elapsed time for the simulation $\left(1 \times 10^{-4} \mathrm{~s}\right)$ is less than the time required to diffuse the copper from Alloy 2 to reach the three points; therefore, the pure aluminum still exists in Alloy 1 domain.
$1(10 \mathrm{~nm})$ for $T_{1}$ equal to 665,675 , and $690^{\circ} \mathrm{C}$, e and $\mathbf{f}$ typical light optical microstructure images for the experiments Ex9 and Ex10 listed in Table 1, e Ex9 and f Ex10

Further in Fig. $6 \mathrm{f}$, the minimum temperature $\left(T_{\mathrm{C}}\right)$ at the points was $627.5,635.3$, and $640.5^{\circ} \mathrm{C}$, which occurred at the time change from $2.5 \times 10^{-6}, 4.4 \times 10^{-6}$, and $6.4 \times 10^{-6}$ $\mathrm{s}$, resulting in an average cooling rate $\left(\left(T_{\mathrm{Liq}}-T_{\mathrm{C}}\right) / t\right)$ of $1.4 \times 10^{7}, 6.1 \times 10^{6}$ and $3.6 \times 10^{6}{ }^{\circ} \mathrm{C} / \mathrm{s}$ and $\Delta T$ of 32,25 , and $20^{\circ} \mathrm{C}$, respectively. According to the above, the spontaneous nucleation dismisses far from the copper diffusion length in pure aluminum area, although the high cooling rate and undercooling exist. The homogeneous nucleation for pure aluminum requires $\Delta T$ around 190 and $175 \mathrm{~K}$ as reported by Turnbull and Kelton, respectively [10]. The nuclei occurring from spontaneous nucleation can be controlled to employ as a self-grain refiner, and this will be the future work.

Figure $7 a-c$ shows the typical optical microstructure images for CDS experiments named Ex6, Ex7, and Ex8 in Table 1 mixed through a 6-mm-diameter funnel with $\mathrm{mr} 6$ at $T_{1}$ equal to 667,675 , and $687^{\circ} \mathrm{C}$, respectively. Figure $7 \mathrm{a}$ reveals a globular with few rosette shape grains forming in the entire microstructure with an average grain size between 175 and $200 \mu \mathrm{m}$ without adding grain refiner, demonstrating that the grain growth is in a stable condition. Figure $7 \mathrm{~b}$ reveals the rosette shape grains with a few globular and dendritic microstructure forming in the entire microstructure with an average grain size between 400 and $450 \mu \mathrm{m}$, which shows the grain growth in partially stable condition. Figure $7 \mathrm{c}$ reveals the dendrite forming 
in an entire microstructure with an average grain size between 1400 and $1500 \mu \mathrm{m}$, indicating that the growth is an unstable condition. The smaller grain size with mixed microstructure appears when Alloy 1 was mixed at superheat less than $10^{\circ} \mathrm{C}$, revealing that a copious heterogeneous and spontaneous nucleation occurs during and after the mixing step. Figure $7 \mathrm{~d}$ shows the simulation results for the cooling curve and $C_{\mathrm{cu}}$ at point $1(10 \mathrm{~nm})$ for CDS experiments named Ex6, Ex7, and Ex8 simulated for $T_{1}$ of 665,675 , and $690{ }^{\circ} \mathrm{C}$ with $\mathrm{mr} 6$ and $T_{2}$ fixed to $555^{\circ} \mathrm{C}$. In Fig. $7 \mathrm{~d}, T_{\mathrm{C}}$ changes from $608.5,612$, and $620^{\circ} \mathrm{C}$ for $T_{1}$ of 665,675 , and $690^{\circ} \mathrm{C}$, respectively; therefore, $\Delta T$ increases for the lower $T_{1}$ resulting in an increase in the nucleation rate and decrease in the grain size. The conventional casting experiment named Ex9 was designed to enhance the heterogeneous nucleation by pouring $\mathrm{Al}-4.7 \mathrm{wt} \% \mathrm{Cu}$ into hot empty crucible preheated to $560^{\circ} \mathrm{C}$ (approximately the same as Alloy 2 temperature in the CDS experiments); the $\Delta T$ employed by Alloy 2 effect was omitted. Figure $7 \mathrm{e}$ shows the typical optical microstructure for Ex9, revealing that dendrites with average size approximately $1500 \mu \mathrm{m}$ dominate in the entire microstructure. Figure $7 f$ shows the typical optical microstructure for conventional casting named Ex10 in Table 1, showing that dendrites having an average grain size of more than $3 \mathrm{~mm}$ dominate the entire microstructure. One can suggest that the improvement in the spontaneous nucleation occurring during the mixing step between Alloy 1 and Alloy 2 is a better way to form a smaller grain size with a non-dendritic microstructure without adding grain refiner.

\section{Summary}

The present study is focused on providing a better understanding of the nucleation events occurring in the supersaturated solution that can establish in the CDS process. Pure aluminum at different temperatures was mixed into Al-33 wt\% Cu eutectic alloys through a 6-mm-diameter funnel with $\mathrm{mr} 6$ to produce a resultant alloy (Alloy 3 ) with 4.7 wt $\% \mathrm{Cu}$. Mixtures made via CDS process and molten alloys from Alloy 3 were quenched by a copper wheel and liquid quenchant to provide more understanding for the nucleation events. The heat and solute equations were solved numerically by the CFD technique to find the redistribution of the temperature, solute, and to find the undercooling required to take place spontaneous nucleation. The conclusions can be summarized as follows:

1. The CDS process can be involved in high cooling rate processes. A higher cooling rate with sufficient undercooling occurs near the boundary between Alloy 1 and Alloy 2 and decreases far from the boundary. The undercooling and the cooling rate strongly depend on $T_{1}, T_{2}$, and $\mathrm{mr}$. The undercooling is sufficient to create spontaneous nucleation from a supersaturated liquid. The nucleation begins in higher liquidus temperature alloy starting near the boundary with lower liquidus temperature alloy. The nuclei can act as a catalyst for the second nucleation taking place from the rest of the supersaturation solution, resulting in a microstructure with small grain size, where a grain refiner does not need to be added.

2. Heterogeneous nucleation takes place in the mixture at the crucible wall depending on the crucible temperature. The heterogeneous nucleation occurs from higher liquidus temperature alloy during the mixing step.

3. Two-step nucleation theory can be employed to introduce a better explanation of the spontaneous nucleation events in an undercooled supersaturation solution.

4. The effect of the latent heat of fusion issued from the nucleation has a limited effect on the nucleation events in the CDS process, contrary to the conventional casting.

5. The model used in the present study provides a better understanding of the cooling curve, temperature distribution, and solute distribution in the CDS process.

The simulation results match the experimental results and provide a better understanding of the nucleation in the supersaturation solution occurring during the CDS process.

Acknowledgements The authors are grateful to Mr. Doug Culley, Mr. Xiaogang Li, and Xiaochun Zheng for helping to use the Factsage software and optical microscope.

\section{Compliance with ethical standards}

Conflict of interest The authors declare that they have no conflict of interest.

\section{References}

1. Khalaf AA (2010) Controlled diffusion solidification: process mechanism and parameter study. Ph.D Thesis, McMaster University

2. Ghiaasiaan R, Zeng X, Shankar S (2014) Controlled diffusion solidification (CDS) of Al-Zn-Mg-Cu (7050): microstructure, heat treatment and mechanical properties. Mater Sci Eng, A 594:260-277

3. Khalaf AA, Shankar S (2012) Effect of mixing rate on the morphology of primary Al phase in the controlled diffusion solidification (CDS) process. J Mater Sci 47:8153-8166

4. Pourgharibshahi $M$, Divandari $M$, Saghafian Larijani $H$, Ashtari $P$ (2017) Controlled diffusion solidification processing: a review. J 
Mater Process Technol 250:203-219. https://doi.org/10.1016/j. jmatprotec.2017.07.018

5. Khalaf AA (2016) Mechanism of controlled diffusion solidification: mixing, nucleation and growth. Acta Mater 103:301-310

6. Ferreira AF, Chrisóstimo WB, Sales RC et al (2019) Effect of pouring temperature on microstructure and microsegregation of as-cast aluminum alloy. Int J Adv Manuf Technol 104:957-965. https://doi.org/10.1007/s00170-019-03979-6

7. Ferreira AF, Paradela KG, Felipe P et al (2017) Phase-field simulation of microsegregation and dendritic growth during solidification of hypoeutectic Al-Cu alloys. Mater Res 20:423-429. https ://doi.org/10.1590/1980-5373-MR-2016-0194

8. Apelian D, Makhlouf MM, Saha D (2006) CDS method for casting aluminum-based wrought alloy compositions: theoretical framework. Mater Sci Forum 519-521:1771-1776

9. Symeonidis K (2009) The controlled diffusion solidification process: fundamentals and principles. Ph.D Thesis, Worcester Polytechnic Institute (WPI)

10. Stefanescu DM (2009) Science and engineering of casting solidification, 3rd edn. Springer, New York

11. Qi XB, Chen Y, Kang XH et al (2015) An analytical approach for predicting as-cast grain size of inoculated aluminum alloys. Acta Mater 99:337-346. https://doi.org/10.1016/j.actam at.2015.08.006

12. Greer AL, Bunn AM, Tronche A et al (2000) Modelling of inoculation of metallic melts: application to grain refinement of aluminum by Al-Ti-B. Acta Mater 48:2823-2835

13. Khalaf AA, Ashtari P, Shankar S (2009) Formation of nondendritic primary aluminum phase in hypoeutectic alloys in controlled diffusion solidification (CDS): a hypothesis. Metall Mater Trans B 40:843-849

14. Khalaf AA, Ashtari P, Shankar S (2009) Controlled diffusion solidification (CDS): conditions for non-dendritic primary aluminum phase in Al-Cu hypo-eutectic alloys. In: The third international symposium, TMS (The Minerals, Metals \& Materials Society), pp 215-222

15. Erdemir D, Lee AY, Myerson AS (2009) Nucleation of crystals from solution: classical and two-step models. Acc Chem Res 42:621-629

16. Van Meel JA, Page AJ, Sear RP, Frenkel D (2008) Two-step vaporcrystal nucleation close below triple point. J Chem Phys. https ://doi.org/10.1063/1.3026364

17. Vekilov PG (2010) The two-step mechanism of nucleation of crystals in solution. R Soc Chem 2:2346-2357. https://doi. org/10.1039/c0nr00628a

18. Peng $Y$, Wang F, Wang $Z$ et al (2015) Two-step nucleation mechanism in solid-solid phase transitions. Nat Mater 14:101-108. https://doi.org/10.1038/nmat4083

19. Black J (2016) Solvent \& additive effects on the appearance of polymorphs of P-aminobenzoic acid. Ph.D Thesis, The University of Manchester

20. Khalaf AA, Shankar S (2011) Favorable environment for a nondendritic morphology in controlled diffusion solidification. Metall Mater Trans A 42:2456-2465

21. Vishan V, Narlikar AV (1976) Structure and superconductivity of splat quenched $\mathrm{Pb}-\mathrm{Bi}$ solid solutions. Mater Res Bull 11:1257-1264

22. Zhou ZM, Xiao ZP, Wei BW et al (2012) The numerical simulation of rapidly solidified Cu-Cr alloys. Procedia Eng 29:3944-3948. https://doi.org/10.1016/j.proeng.2012.01.599

23. Chattopadhyay C, Sangal S, Mondal K (2010) A relook at the preferred growth direction of the solid-liquid interface during solidification of pure metals. Acta Mater 58:5342-5353. https:// doi.org/10.1016/j.actamat.2010.06.009
24. Rocha OL, Siqueira CA, Garcia A (2003) Heat flow parameters affecting dendrite spacings during unsteady-state solidification of Sn-Pb and Al-Cu alloys. Metall Mater Trans A 34(4):995-1006. https://doi.org/10.1007/s11661-003-0229-3

25. Koutsoukos PG, Kofina AN, Kanellopoulou DG (2007) Solubility of salts in water: key issue for crystal growth and dissolution processes. Pure Appl Chem 79:825-850. https://doi.org/10.1351/ pac200779050825

26. McFadden S, Browne DJ (2012) A generalized version of an Ivantsov-based dendrite growth model incorporating a facility for solute measurement ahead of the tip. Comput Mater Sci 55:245-254. https://doi.org/10.1016/j.commatsci.2011.12.011

27. Jian Z, Kuribayashi K, Jie W (2005) Solid-liquid interface energy of metals at melting point and undercooled state. Mater Trans 43:721-726. https://doi.org/10.2320/matertrans.43.721

28. Jácome PAD, Moutinho DJ, Gomes LG et al (2012) The application of computational thermodynamics for the determination of surface tension and Gibbs-Thomson coefficient of aluminum ternary alloys. Mater Sci Forum 730-732:871-876. https://doi. org/10.4028/www.scientific.net/msf.730-732.871

29. Sosso GC, Chen J, Cox SJ et al (2016) Crystal nucleation in liquids: open questions and future challenges in molecular dynamics simulations. Chem Rev 116:7078-7116. https://doi.org/10.1021/ acs.chemrev.5b00744

30. Perepezko JH (1994) Nucleation reactions in undercooled liquids. Mater Sci Eng, A 178:105-111. https://doi. org/10.1016/0921-5093(94)90527-4

31. Gremaud M, Allen DR, Rappaz M, Perepezko JH (1996) The development of nucleation controlled Al-Si alloys. Acta Mater 44:2669-2681

32. Pop II, Ingham DB (2001) Convective Heat Transfer. Elsevier Science \& Technology Books, London

33. Du Y, Chang Y, Huang B et al (2003) Diffusion coefficients of some solutes in fcc and liquid Al: critical evaluation and correlation. Mater Sci Eng, A 363:140-151

34. Kurz W, Fisher DJ (1984) Fundamentals of solidification, 2nd edn. Trans Tech Publications, Aedermannsdorf

35. Wu M, Ludwig A (2009) Modeling equiaxed solidification with melt convection and grain sedimentation-II. Model verification. Acta Mater 57:5632-5644. https://doi.org/10.1016/j.actam at.2009.07.067

36. Valencia JJ, Quested PN (2008) ASM handbook committee/thermophysical properties, pp 468-481

37. Bala KC, Khan RH (2014) Rate of solidification of aluminium casting in varying wall thickness of cylindrical metallic moulds. Leonardo J Sci (25):19-30

38. Vekilov PG (2010) The two-step mechanism of nucleation of crystals in solution. Nanoscale 2:2346-2357. https://doi. org/10.1039/c0nr00628a

39. Zhang DL, Chattopadhyay K, Cantor B (1991) Heterogeneous nucleation of solidification of cadmium particles embedded in an aluminium matrix. J Mater Sci 26:1531-1544. https://doi. org/10.1007/BF00544662

40. Qian M, Cao P, Easton MA et al (2010) An analytical model for constitutional supercooling-driven grain formation and grain size prediction. Acta Mater 58:3262-3270. https://doi. org/10.1016/j.actamat.2010.01.052

Publisher's Note Springer Nature remains neutral with regard to jurisdictional claims in published maps and institutional affiliations. 